\title{
Human immunodeficiency virus in a cohort of systemic lupus erythematosus patients
}

\author{
Vanessa Hax ${ }^{1^{*}} \mathbb{D}$, Ana Laura Didonet Moro ${ }^{1}$, Rafaella Romeiro Piovesan², Luciano Zubaran Goldani ${ }^{3}$, \\ Ricardo Machado Xavier ${ }^{1}$ and Odirlei Andre Monticielo ${ }^{1}$
}

\begin{abstract}
Background: Systemic lupus erythematosus (SLE) and acquired immunodeficiency syndrome (AIDS) share many clinical manifestations and laboratory findings, therefore, concomitant diagnosis of SLE and human immunodeficiency virus (HIV) can be challenging.

Methods: Prospective cohort with 602 patients with SLE who attended the Rheumatology Clinic of the Hospital de Clínicas de Porto Alegre since 2000. All patients were followed until 01 May 2015 or until death, if earlier. Demographic, clinical and laboratory data were prospectively collected.

Results: Out of the 602 patients, 11 presented with the diagnosis of AIDS (1.59\%). The following variables were significantly more prevalent in patients with concomitant HIV and SLE: neuropsychiatric lupus (10.9\% vs. 36.4\%; $p=0.028$ ) and smoking ( $37.6 \%$ vs. $80 \% ; p=0.0009)$ while malar rash was significantly less prevalent in this population ( $56 \%$ vs. $18.2 \%$; $p=0.015)$. Nephritis (40.5\% vs. $63.6 \% ; p=0.134)$ and hemolytic anemia ( $28.6 \%$ vs. $54.5 \% ; p=0.089)$ were more prevalent in SLE patients with HIV, but with no statistical significance compared with SLE patients without HIV. The SLICC damage index median in the last medical consultation was significantly higher in SLE patients with HIV (1 vs. 2; $p=0,047)$.

Conclusions: Our patients with concomitant HIV and SLE have clinically more neuropsychiatric manifestations. For the first time, according to our knowledge, higher cumulative damage was described in lupus patients with concomitant HIV infection. Further studies are needed to elucidate this complex association, its outcomes, prognosis and which therapeutic approach it's best for each case.
\end{abstract}

Keywords: Systemic lupus erythematosus, Human immunodeficiency virus, Acquired immunodeficiency syndrome, Neuropsychiatric lupus, Opportunistic infections

\section{Background}

Concomitant diagnosis of systemic lupus erythematosus (SLE) and acquired immunodeficiency syndrome (AIDS) can be intriguing and challenging. SLE and human immunodeficiency virus (HIV) infection share many clinical manifestations, including musculoskeletal symptoms such as myalgia, arthralgia/arthritis, skin rashes, lymphadenopathy and organ involvement, such as kidneys, heart, lungs and central nervous system [1]. They also have several common laboratory findings such as anemia, leukopenia, lymphopenia, thrombocytopenia and hypergammaglobulinemia [1].

\footnotetext{
* Correspondence: vanessahax@gmail.com.br; vanessahax@gmail.com ${ }^{1}$ Division of Rheumatology, Hospital de Clínicas de Porto Alegre, Universidade Federal do Rio Grande do Sul, 2350 Ramiro Barcelos St, Room 645, Porto Alegre, RS 90035-903, Brazil

Full list of author information is available at the end of the article
}

There are few studies assessing the clinical and laboratory manifestations in SLE patients with HIV infection, as well as patient's profile and their evolution. Furthermore, there are no studies assessing the prognosis of this association until now. Therefore, the present study aimed to demonstrate the profile of these patients in our center, appointing their clinical and laboratory features, the significant differences between the patients with or without HIV, the treatment offered and their evolution considering infections, other diseases and mortality.

\section{Methods \\ Study population}

This prospective cohort consisted of 602 SLE patients who attended the Rheumatology Clinic of the Hospital de Clínicas de Porto Alegre since 2000. All patients

(c) The Author(s). 2018 Open Access This article is distributed under the terms of the Creative Commons Attribution 4.0 International License (http://creativecommons.org/licenses/by/4.0/), which permits unrestricted use, distribution, and 
fulfilled the American College of Rheumatology (ACR) revised criteria for the classification of SLE [2] and an informed consent form was obtained from all participants. The patients were followed until 01 May 2015 or until death, if earlier. The demographic, clinical and laboratory data were prospectively collected.

\section{Clinical and laboratory variables}

The following variables were recorded: age, gender, age at diagnosis of SLE and HIV (when the last was positive) , smoking status (current or previous), cardiovascular diseases, dyslipidemia, other autoimmune diseases and treatment performed. Clinical manifestations of SLE included the presence of photosensitivity, malar rash, discoid rash, oral or nasal ulcers, arthritis, serositis (pleuritis or pericarditis), nephritis and neurological disease, defined as seizures or psychosis. The assessment of the group of patients with concomitant HIV included infections, as well as CD4 and viral load at the diagnosis and the last count available. The laboratory evaluation included the presence of hematological disorders (hemolytic anemia, leukopenia, lymphopenia or thrombocytopenia), positive antinuclear antibody (ANA) (titer $>1: 80$ ) or other autoantibodies such as antidsDNA, anti-Sm, anti-RNP, anti-Ro, anti-La, anticardiolipin (aCL), lupus anticoagulant and false positive VDRL. The patients were also evaluated in regard to secondary antiphospholipid syndrome and secondary Sjogren's syndrome, according to the classification criteria for both diseases $[3,4]$. The SLEDAI and the SLICC damage index of the last medical consultation were recorded too, as a measurement of disease activity and cumulative damage, respectively [5]

\section{Statistical analyses}

A descriptive analysis of data through calculation of mean and standard deviation (SD) for quantitative variables was performed while the frequency and percentage were calculated for categorical variables. The median and interquartile range were calculated to quantitative variables with asymmetrical distribution. We used the chi square test or Fisher's exact test to compare categorical variables, and continuous variable were analyzed with Mann-Whitney test. All statistical analyses were performed using SPSS 20.0. All tests were performed at the 0.05 level of significance and were two-sided.

\section{Results}

Our study consisted of 602 SLE patients, 75.2\% European derived, 92\% female and 11 (1.59\%) of these patients presented with HIV. The patients mean age was $42.8 \pm 12.7$ years and the mean SLE diagnostic age was $29.9 \pm 13.9$ years. Demographic, clinical and laboratory profile were showed in Table 1 . The following variables were significantly more prevalent in patients with concomitant HIV and SLE: neuropsychiatric lupus $(10.9 \%$ vs. $36.4 \% ; p=0.028)$ and smoking (37.6\% vs. $80 \% ; p=0.0009)$ while malar rash was significantly less prevalent in this population $(56 \%$ vs. $18.2 \% ; p=0.015)$. The following features were more prevalent in SLE patients with HIV, but without to reach statistical significance compared with SLE patients without HIV: nephritis (40.5\% vs. 63.6\%; $p=0.134)$, hemolytic anemia $(28.6 \%$ vs. $54.5 \%$; $p=0.089)$, presence of anti-Ro $(39.4 \%$ vs. $63.6 \% ; p=0.125)$ and anti-La $(13.1 \%$ vs. $27.3 \% ; p=0.172)$, cardiovascular disease $(18.1 \%$ vs. $36.4 \%$; $p=0.126)$ and diabetes mellitus (7.7\% vs. $18.2 \% ; p=0.212)$. Regarding the autoantibodies, in our cohort, amongst SLE patients with HIV, 72.7\% had positive Coomb's test, $45.5 \%$ anti-dsDNA, 9.1\% anti-Sm, 63.6\% anti-Ro, 27.3\% anti-La, 27.3\% anti-RNP and 9.1\% antiphospholipid antibodies. Hypergammaglobulinemia and hypocomplementenemia were observed in $81.8 \%$ of SLE patients with HIV.

The survival rate was $96.6 \%$ and $93.5 \%$ in 5 and 10 years, respectively, in SLE patients without HIV. Meanwhile, the survival rate was $90 \%$ in 5 and 10 years in SLE patients with HIV. There was no significant difference between the two groups. The SLICC damage index median in the last medical consultation was significantly higher in SLE patients with HIV (1 vs. 2; $p=0.047)$. The median of the last SLEDAI did not reach significant difference between groups ( 0 vs. $1 ; p=0.55$ ). In the HIV group, infections occurred in $54.5 \%$, predominantly human papillomavirus infection, followed by tuberculosis and herpes zoster infection. Coinfection with $C$ hepatitis virus occurred in two patients (18\%).

Simultaneous diagnosis of SLE and HIV infection was done in one patient, while HIV following SLE was diagnosed in eight patients and HIV infection preceded SLE in two patients. All the patients were female and at diagnosis of HIV the mean CD4 count was 296 cells/ $\mu \mathrm{L}$ and HIV-RNA 60.000 copies $/ \mathrm{ml}$. Antiretroviral therapy (ART) was taken by all the patients and, considering SLE, seven were treated with hydroxychloroquine (HCQ), two with azathioprine (AZA), two with cyclophosphamide (CYC), one with methotrexate (MTX) and one with mycophenolate mofetil (MMF), according to the severity of each case (Table 2).

\section{Discussion}

The coexistent infection of HIV and SLE is unusual and intriguing, because both diseases are characterized by multisystem involvement and immune dysfunction related to $\mathrm{T}$ lymphocytes, cytokine production alterations and polyclonal activation of B lymphocytes [6]. Despite these similarities, several theories have been formulated to explain the reason of the unexpectedly lower prevalence of concomitant diagnosis of HIV and SLE. SLE may prevent HIV infection as a result of polyclonal 
Table 1 Demographic, clinical, and laboratory features of SLE patients with and without HIV infection

\begin{tabular}{|c|c|c|c|c|}
\hline Patients features & All patients $(n=602)$ & $\begin{array}{l}\text { SLE patients without HIV } \\
(n=591)\end{array}$ & $\begin{array}{l}\text { SLE patients with HIV } \\
(n=11)\end{array}$ & $P$ value \\
\hline Females & $92 \%(602)$ & $91.9 \%(591)$ & $100 \%(11)$ & 1.000 \\
\hline European derived & $75.2 \%(584)$ & $75.4 \%(573)$ & $63.6 \%(11)$ & 0.479 \\
\hline Smoking $^{b}$ & $38.3 \%(582)$ & $37.6 \%(215)$ & $80 \%(11)$ & 0.009 \\
\hline Obesity & $25.3 \%(502)$ & $25.9 \%(127)$ & $0 \%(11)$ & 0.074 \\
\hline Age (years) & $48.2 \pm 14.9(597)$ & $48.3 \pm 14.9(586)$ & $43.1 \pm 12.7(11)$ & 0.245 \\
\hline SLE age at diagnosis (years) & $33.5 \pm 14.2(591)$ & $33.6 \pm 14.2(580)$ & $29.9 \pm 13.9(11)$ & 0.390 \\
\hline Malar rash & $55.3 \%(597)$ & $56 \%(586)$ & $18.2 \%(11)$ & 0.015 \\
\hline Photosensitivity & $72.1 \%(598)$ & $72.4 \%(587)$ & $54.5 \%(11)$ & 0.191 \\
\hline Oral ulcers & $35.6 \%(598)$ & $35.6 \%(587)$ & $36.4 \%(11)$ & 1.000 \\
\hline Arthritis & $72.4 \%(597)$ & $74.4 \%(586)$ & $63.6 \%(11)$ & 0.486 \\
\hline Serositis & $25.2 \%(595)$ & $25 \%(585)$ & $36.4 \%(11)$ & 0.482 \\
\hline Nephritis & $40.9 \%(596)$ & $40.5 \%(585)$ & $63.6 \%(11)$ & 0.134 \\
\hline Neurologic disorders & $11.4 \%(596)$ & $10.9 \%(585)$ & $36.4 \%(11)$ & 0.028 \\
\hline Psychosis & $6.5 \%(597)$ & $6.3 \%(586)$ & $18.2 \%(11)$ & 0.158 \\
\hline Seizures & $6 \%(597)$ & $6 \%(586)$ & $9.1 \%(11)$ & 0.498 \\
\hline Hematologic disorders & $75.8 \%(598)$ & $75.8 \%(587)$ & $72.7 \%(11)$ & 0.773 \\
\hline Hemolytic anemia & $29.1 \%(598)$ & $28,6 \%(587)$ & $54,5 \%(11)$ & 0.089 \\
\hline Leukopenia/Lymphopenia & $55.9 \%(598)$ & $56 \%(587)$ & $45.5 \%(11)$ & 0.549 \\
\hline Thrombocytopenia & $21.4 \%(598)$ & $21.5 \%(587)$ & $18.2 \%(11)$ & 1.000 \\
\hline Anti-dsDNA & $46 \%(567)$ & $46 \%(556)$ & $45.5 \%(11)$ & 1.000 \\
\hline Anti-Sm & $20.8 \%(549)$ & 21\% (538) & $9.1 \%(11)$ & 0.474 \\
\hline Anticardiolipin & $27.3 \%(550)$ & $27.6 \%(539)$ & $9.1 \%(11)$ & 0.304 \\
\hline Lupus Anticoagulant & $10 \%(548)$ & $10.1 \%(537)$ & $9.1 \%(11)$ & 1.000 \\
\hline Anti-Ro & $39.9 \%(516)$ & $39.4 \%(505)$ & $63.6 \%(11)$ & 0.125 \\
\hline Anti-La & $13.4 \%(515)$ & $13.1 \%(504)$ & $27.3 \%(11)$ & 0.172 \\
\hline Anti-RNP & $31.1 \%(515)$ & $31.2 \%(504)$ & $27.3 \%(11)$ & 1.000 \\
\hline SLEDAI (median) ${ }^{c}$ & $1(415)$ & $1(407)$ & $0(11)$ & 0.550 \\
\hline SLICC damage index (median) ${ }^{c}$ & 1 (559) & $1(551)$ & $2(11)$ & 0.047 \\
\hline
\end{tabular}

Abbreviations: SLE systemic lupus erythematosus, SLEDAI systemic lupus erythematosus disease activity index, SLICC systemic lupus international collaborating clinics, HIV human immunodeficiency virus

${ }^{a}$ Chi square test for qualitative variables and Mann-Whitney test for quantitative variables

${ }^{\mathrm{b}}$ Current or past smoker

${ }^{c}$ Median (interquartile interval)

antibody stimulation [7] and treatment with antimalarials [8]. Patients with SLE have higher levels of interleukin (IL)-16 and IL-16 inhibits HIV infection in vitro, representing a possible protective role against HIV in SLE patients [9]. Likewise, SLE cannot develop in the setting of CD4 cell depletion seen in HIV [10]. Zandman-Goddard and Shoenfeld proposed that autoimmune manifestations in patients with HIV occur after the restoration of immunological competence (CD4 count $>500$ cells $/ \mu \mathrm{L}$ and low viral load) using ART or during the first stage of HIV (the acute HIV infection), when the immune system is intact and, hence, autoimmune diseases may present [11].

Kopelman and Zolla-Pazner published in 1988 the first report of a patient with HIV infection and SLE [12].
Since then, there have been several case reports or small case series of patients with concomitant SLE and HIV. Literature review has identified a total of 58 patients reported until 2014, some of which did not fulfill the criteria for SLE [1]. Then, in 2014, Mody et al. published a relatively large case series of 13 patients with coexistent HIV infection and SLE evaluated in a hospital of Durban, South Africa [1].

Kopelman and Zolla-Pazner have tested 151 consecutive patients with HIV and found that 19 had positive ANA, most of it in low titers, which usually is not associated with clinical manifestations of SLE [12]. Medina-Rodriguez et al. also found a significant number of HIV-positive patients with positivity for aCL IgG (94\%), and aCL IgM (44\%) [13]. 
Table 2 Demographic, clinical and laboratory features, treatment and outcome of SLE patients with HIV

\begin{tabular}{|c|c|c|c|c|c|c|c|c|c|}
\hline Case & Gender & First DX & Clinical features & Autoantibodies & SLE treatment & ART & CD4 at DXa & Last CD4 & Outcome \\
\hline 1 & $F$ & SLE & $\begin{array}{l}\text { Discoid lupus, } \\
\text { photosensitivity, } \\
\text { oral ulcers and arthritis }\end{array}$ & ANA and anti-Ro & $\mathrm{CS}$ & Yes & 434 & 337 & $\begin{array}{l}\text { Good health condition, } \\
\text { but loss of follow-up in } \\
\text { the Rheumatology Clinic }\end{array}$ \\
\hline 2 & $\mathrm{~F}$ & SLE & $\begin{array}{l}\text { Raynaud, arthritis } \\
\text { and vasculitis }\end{array}$ & $\begin{array}{l}\text { ANA, anti-dsDNA, } \\
\text { anti-Ro and anti-La }\end{array}$ & CS & Yes & 572 & 205 & $\begin{array}{l}\text { Disseminated TB at } \\
\text { 2015, follow-up in the } \\
\text { Infectious Diseases Clinic }\end{array}$ \\
\hline 3 & $\mathrm{~F}$ & SLE & $\begin{array}{l}\text { Arthritis, leucopenia, } \\
\text { lymphopenia, alopecia, } \\
\text { Raynaud and photosensitivity }\end{array}$ & ANA & $\mathrm{HCQ}$ & Yes & 424 & 1056 & $\begin{array}{l}\text { SLE in remission, } \\
\text { HIV controlled }\end{array}$ \\
\hline 4 & $\mathrm{~F}$ & SLE & $\begin{array}{l}\text { Discoid lupus, } \\
\text { photosensitivity, nephritis, } \\
\text { leucopenia and lymphopenia }\end{array}$ & ANA & $\mathrm{HCQ}$ & Yes & 149 & 524 & $\begin{array}{l}\text { HCV coinfection } \\
\text { SLE in remission } \\
\text { and HIV controlled }\end{array}$ \\
\hline 5 & $\mathrm{~F}$ & SLE & $\begin{array}{l}\text { Photosensitivity, oral ulcers, } \\
\text { arthritis and nephritis }\end{array}$ & $\begin{array}{l}\text { ANA, anti-Ro } \\
\text { and anti-La }\end{array}$ & $\begin{array}{l}\mathrm{CS}, \mathrm{AZA} \rightarrow \mathrm{MMF} \text { and } \\
\text { tacrolimus }\end{array}$ & Yes & 273 & 991 & $\begin{array}{l}\text { Pulmonary TB in 2008, } \\
\text { kidney transplantation } \\
\text { in } 2011\end{array}$ \\
\hline 6 & $\mathrm{~F}$ & SLE & $\begin{array}{l}\text { Photosensitivity, serositis } \\
\text { and arthritis }\end{array}$ & ANA & None & Yes & 172 & 391 & $\begin{array}{l}\text { HCV coinfection, } \\
\text { SLE in remission } \\
\text { and HIV controlled }\end{array}$ \\
\hline 7 & $\mathrm{~F}$ & SLE & $\begin{array}{l}\text { Alopecia, arthritis, nephritis, } \\
\text { hemolytic anemia and } \\
\text { hypergammaglobulinemia }\end{array}$ & $\begin{array}{l}\text { ANA, anti-dsDNA } \\
\text { and anti-Ro }\end{array}$ & $\begin{array}{l}\mathrm{HCQ}, \mathrm{CYC} \\
\rightarrow \mathrm{AZA}\end{array}$ & Yes & 321 & 165 & $\begin{array}{l}\text { Good initial response, } \\
\text { poor adherence to } \\
\text { treatment with } \\
\text { posterior reactivation } \\
\text { of nephritis and CD4 } \\
\text { count drop }\end{array}$ \\
\hline 8 & $\mathrm{~F}$ & HIV & $\begin{array}{l}\text { Hemolytic anemia, serositis, } \\
\text { oral ulcers and arthritis }\end{array}$ & $\begin{array}{l}\text { ANA, anti-Sm } \\
\text { and anti-RNP }\end{array}$ & $\mathrm{HCQ}, \mathrm{MTX}$ & Yes & NA & 477 & $\begin{array}{l}\text { CMV Retinitis in 2006, } \\
\text { SLE in remission and } \\
\text { HIV controlled }\end{array}$ \\
\hline 9 & F & HIV & $\begin{array}{l}\text { Hemolytic anemia } \\
\text { and nephritis }\end{array}$ & $\begin{array}{l}\text { ANA and } \\
\text { anti-dsDNA }\end{array}$ & $\begin{array}{l}\mathrm{CS}, \mathrm{HCQ} \\
\mathrm{CYC} \rightarrow \mathrm{AZA}\end{array}$ & Yes & 235 & 252 & $\begin{array}{l}\text { Complete response } \\
\text { to CYC, posterior } \\
\text { poor adherence } \\
\text { and loss of follow-up } \\
\text { due to drug addiction }\end{array}$ \\
\hline 10 & $\mathrm{~F}$ & SLE & $\begin{array}{l}\text { Hemolytic anemia, serositis, } \\
\text { leucopenia, lymphopenia, } \\
\text { oral ulcers, arthritis } \\
\text { and nephritis }\end{array}$ & $\begin{array}{l}\text { ANA and } \\
\text { anti-dsDNA }\end{array}$ & $\mathrm{HCQ}$ & Yes & 203 & 323 & $\begin{array}{l}\text { SLE in remission and } \\
\text { HIV controlled }\end{array}$ \\
\hline 11 & $\mathrm{~F}$ & Both & $\begin{array}{l}\text { Alopecia, hemolytic anemia, } \\
\text { nephritis, thrombocytopenia, } \\
\text { leucopenia and lymphopenia }\end{array}$ & ANA & $\begin{array}{l}\mathrm{CS}, \mathrm{HCQ} \\
\rightarrow \mathrm{AZA}\end{array}$ & Yes & 111 & NA & $\begin{array}{l}\text { Both diagnosed in } \\
\text { hospital stay, } \\
\text { progressing to death } \\
\text { from sepsis }\end{array}$ \\
\hline
\end{tabular}

Abbreviations: $A C L \lg G$ anti-cardiolipin IgG, $A C L \lg M$ anti-cardiolipin $\lg \mathrm{M}, A N A$ anti-nuclear antibody, $A R T$ active antiretroviral therapy, $A Z A$ azathioprine, $C M V$ cytomegalovirus, CS corticosteroids, CYC cyclophosphamide, dsDNA anti-double-stranded DNA, DX diagnosis, $F$ female, $H C Q$ hydroxychloroquine, $H I V$ human immunodeficiency virus, $M$ male, MMF mycophenolate mofetil, MTX methotrexate, NA not available, SLE systemic lupus erythematosus, $T B$ tuberculosis

${ }^{a} \mathrm{CD} 4$ cell count at diagnosis of HIV-infection: cells $/ \mathrm{mm}^{3}$

However, Petrovas et al. in a case-control study that compared the prevalence of antiphospholipid antibodies in patients with HIV infection, SLE with or without antiphospholipid syndrome (APS) and in primary antiphospholipid syndrome (PAPS), also evaluating the reactivity of these antibodies with $\beta 2$ glicoprotein (GPI). It was demonstrated that the prevalence of aCL antibodies in HIV-infection was $36 \%$. However, anti- $\beta 2-$ GPI occurred in only $5 \%$ of HIV, which seems to reduce its thrombogenic potential [14]. Therefore, antiphospholipid antibodies occur in HIV-1 infection, but are not associated with thrombosis [14]. In our cohort, prevalence of antiphospholipid antibodies did not differ between patients with and without infection by HIV.

Additional studies evaluated the presence of other autoantibodies in HIV-positive patients and found multiple autoimmune phenomena HIV-associated, many of those seen in SLE, including besides the presence of ANAs, antiplatelet antibodies, antilymphocyte antibodies and antineutrophil cytoplasmic antibodies (ANCA), as well as Coomb's positivity, circulating immune complexes, rheumatoid factor and cryoglobulins [7, 13, 15, 16]. Furthermore, the presence of antibodies to extractable nuclear antigens (ENA) has also been described, although with controversial findings. Muller et al. have tested the 
presence of ENA by enzyme-linked immunosorbent assay (ELISA) in 100 HIV-positive patients, detecting antidsDNA, anti-histone, anti-Sm, anti-RNP and anti-Ro in $45 \%$ to $90 \%$ of these patients [17]. In its turn, Lafeuillade et al. in a study including 119 HIV-positive patients, found a lower frequency of those autoantibodies (4\% had ANAs, $1 \%$ anti-dsDNA, $4 \%$ anti-Sm and 6\% anti-histone) [18]. Thus, the presence of these autoantibodies in HIV patients is still controversial. Variations in the studied populations and in the analysis techniques employed explain, in part, these discrepancies [19]. In one study, the positivity for autoantibodies was significantly associated with lower CD4 lymphocyte counts and with increased mortality, which can indicate a prognostic implication of the autoimmunity in the context of HIV infection [15].

In patients with coexistence of HIV infection and diagnosis of SLE, three patterns of disease occurrence have been described: HIV following SLE diagnosis, SLE following the diagnosis of HIV infection and simultaneous diagnosis of HIV and SLE [20]. In our cohort, the most prevalent pattern was the one in which patients with established SLE were subsequently diagnosed with infection by HIV. Some studies suggest that HIV infection can attenuate the natural history of SLE [10, 21-23]. On the other hand, the impact of SLE in patients with preexisting HIV infection is not well known. Some authors propose that SLE may contribute to a worst outcome of the HIV infection, keeping in mind that there are some reports describing a shorter time span until the development of AIDS in patients with concomitant SLE [23]. Nonetheless, this data is unavailable in many cases and there are some reports in which patients with coexistence of HIV infection and SLE did not developed AIDS even after long periods of observation [19]. Furthermore, some authors believe the immunologic effects of SLE and HIV may antagonize each other, contributing to the uncertainty regarding the clinical impact of this association [23].

Many of the clinical features of SLE overlap with either the primary features or secondary complications of HIV infection [24]: dermatologic findings such as alopecia, oral ulcers and facial rash; constitutional symptoms, including fever and malaise; musculoskeletal involvement such as arthralgias, arthritis and myalgias; renal abnormalities, including hematuria and proteinuria; central nervous system disorders, such as seizures and psychosis; hematologic alterations, including anemia, leucopenia, lymphopenia and thrombocytopenia; and immunologic features such as hypergammaglobulinemia and positive ANA [21, 25]. The term pseudolupus has been used to describe patients with HIV infection that present with rheumatic manifestations similar to SLE. In our cohort, nephritis, neuropsychiatric lupus, hemolytic anemia, hypergammaglobulinemia, presence of anti-Ro and anti-
La were the most prevalent features amongst the SLE patients infected by HIV.

Besides, false positive HIV on ELISA tests have also been described in SLE patients, making the diagnosis even more difficult, and making it necessary to perform other confirmatory tests for HIV [26]. In these cases, viral RNA PCR assays were superior than the p24 antigen assay (less sensitive) to exclude the possibility of a false positive HIV on ELISA test [27]. Low complement due to HIV infection has not been reported. Therefore, hypocomplementenemia may be a helpful test to differentiate lupus activity from HIV-related manifestations [24]. In our cohort the majority of patients with AIDS presented with hypocomplementenemia and this finding contributed not only to assess the disease activity, but also to establish the diagnosis of SLE.

The treatment of patients with coexistent SLE and HIV infection is challenging and there aren't well established therapeutic guidelines thus far. Immunosuppressive medications may have a negative impact in patients with preexistent impaired immunity [25]. However, with the adequate suppression of the HIV viral load, it is postulated that the treatment of SLE would not anticipate the development of AIDS [19]. Associated to ART, HCQ seems to be a reasonable and safe approach, considering it also has antiviral properties in HIV patients [28] and that its anti-inflammatory effect doesn't appear to be associated with an increased risk of opportunistic infections [29]. Low-dose corticosteroids may be considered with caution for those with severe immunosuppression by AIDS [25]. Relative safety of using MMF in HIVpositive patients has been confirmed by its successful use in the solid organ transplantation in HIV patients on ART [30]. Therefore, the risks and benefits have to be considered carefully when deciding the therapeutic approach that is more adequate to each patient with concomitant HIV infection and SLE [20]. Patients of our cohort that used CYC for the induction treatment of nephritis, followed by maintenance with AZA, developed a complete response with no major infectious complications.

It is well known that there is an increased risk of opportunistic infection in SLE patients, as well as in patients infected by HIV and this is the leading cause of morbidity and mortality in both diseases [6]. In our cohort, survival in 5 and 10 years was similar in SLE patients with or without AIDS. Even though we emphasized a statistically significant difference in the SLICC, indicating a greater cumulative damage in patients with concomitant AIDS, the clinical and prognostic relevance of this finding is uncertain thus far, once there was no significant difference in the survival rate between the groups in our study population.

Special attention must also be paid to infections caused by Mycobacterium tuberculosis, due to its high prevalence in HIV patients [31] as well as SLE, especially 
in developing countries [32]. Patients with lupus and HIV seems to have a higher risk of developing tuberculosis as shown by the largest case series available on the subject, in which 7 out of 13 patients were diagnosed with tuberculosis [1]. In our cohort, only 2 patients infected by HIV developed tuberculosis, probably reflecting the demographic differences and the regional prevalences of this disease.

\section{Conclusion}

Patients with concomitant HIV and SLE presented with neuropsychiatric manifestations more often. Therefore, it is essential to pay attention to the early diagnosis of HIV, especially in the scenario of this severe manifestation and in light of the need to intensify the immunosuppression. Moreover, there was a higher prevalence of hypergammaglobulinemia and hypocomplementenemia, which in turn, can be an useful tool to identify disease activity. For the first time, higher cumulative damage was described in lupus patients with concomitant HIV infection, which can contribute to a worst life quality and reduction of the survival rates, although further studies are needed to elucidate this complex association, its outcomes and prognosis.

\section{Abbreviations}

aCL: Anticardiolipin; ACR: AMERICAN College of Rheumatology; AIDS: Acquired immunodeficiency syndrome; ANA: Antinuclear antibody; ANCA: Antineutrophil cytoplasmic antibodies; APS: Antiphospholipid syndrome; ART: Antiretroviral therapy; AZA: Azathioprine;

CYC: Cyclophosphamide; ds-DNA: Anti-double-stranded DNA; ELISA: Enzymelinked immunosorbent assay; ENA: Extractable nuclear antigens; GPI: Glicoprotein; HCQ: Hydroxychloroquine; IL: Interleukin; MMF: Mycophenolate mofetil; MTX: Methotrexate; PAPS: Primary antiphospholipid syndrome; SD: Standard deviation; SLE: Systemic lupus erythematosus; SLEDAI: Systemic Lupus Erythematosus Disease Activity Index; SLICC: Systemic Lupus International Collaborating Clinics

\section{Availability of data and materials}

The datasets used during the current study are available from the corresponding author on reasonable request.

\section{Authors' contributions}

All the authors collaborated in the analysis and in writing the manuscript. All authors read and approved the final manuscript.

\section{Ethics approval and consent to participate}

This study was approved by the Research Ethics Committee of the Hospital de Clínicas de Porto Alegre, and an informed consent form was obtained from all participants.

\section{Competing interests}

The authors declare that they have no competing interests.

\section{Publisher's Note}

Springer Nature remains neutral with regard to jurisdictional claims in published maps and institutional affiliations.

\section{Author details}

'Division of Rheumatology, Hospital de Clínicas de Porto Alegre, Universidade Federal do Rio Grande do Sul, 2350 Ramiro Barcelos St, Room 645, Porto Alegre, RS 90035-903, Brazil. 'Medical School Student, Universidade Federal do Rio Grande do Sul, Porto Alegre, Brazil. ${ }^{3}$ Division of
Infectious Diseases, Hospital de Clínicas de Porto Alegre, Universidade Federal do Rio Grande do Sul, Porto Alegre, Brazil.

Received: 27 February 2018 Accepted: 12 April 2018

Published online: 11 July 2018

\section{References}

1. Mody GM, Patel N, Budhoo A, Dubula T. Concomitant systemic lupus erythematosus and HIV: case series and literature review. Semin Arthritis Rheum. 2014;44(2):186-94.

2. Hochberg MC. Updating the American College of Rheumatology revised criteria for the classification of systemic lupus erythematosus. Arthritis Rheum. 1997:40(9):1725.

3. Vitali C, Bombardieri S, Jonsson R, et al. Classification criteria for Sjögren's syndrome: a revised version of the European criteria proposed by the American-European consensus group. Ann Rheum Dis. 2002;61(6):554-8.

4. Miyakis S, Lockshin MD, Atsumi T, et al. International consensus statement on an update of the classification criteria for definite antiphospholipid syndrome (APS). J Thromb Haemost. 2006;4(2):295-306.

5. Griffiths B, Mosca M, Gordon C. Assessment of patients with systemic lupus erythematosus and the use of lupus disease activity indices. Best Pract Res Clin Rheumatol. 2005:19(5):685-708.

6. Sekigawa I, Okada M, Ogasawara $H$, et al. Lessons from similarities between SLE and HIV infection. J Inf Secur. 2002;44(2):67-72.

7. Kaye BR. Rheumatologic manifestations of HIV infections. Clin Rev Allergy Immunol. 1996;14:385-416.

8. Tsai WP, Nara PL, Kung HF, Oroszlan S. Inhibition of immunodeficiency virus infectivity by chloroquin. AIDS Res Hum Retrovir. 1990;6:481-9.

9. Sekigawa I, Lee $\mathrm{S}$, Kaneko $\mathrm{H}$, et al. The possible role of interleukin-16 in the low incidence of HIV infection in patients with systemic lupus erythematosus. Lupus. 2000;9:155-6.

10. Furie RA. Effects of human immunodeficiency virus infection on the expression of rheumatic illness. Rheum Dis Clin North Am. 1991;17:177-88.

11. Zandman-Goddard G, Shoenfeld Y. HIV and autoimmunity. Autoimmun Rev. 2002;1(6):329-37.

12. Kopelman RG, Zolla-Pazner S. Association of human immunodeficiency virus infection and autoimmune phenomena. Am J Med. 1988;84:82-8.

13. Medina-Rodriguez F, Guzman C, Jara LJ, et al. Rheumatic manifestations in human immunodeficiency virus positive and negative individuals: a study of 2 populations with similar risk factors. J Rheumatol. 1993;20:1880-4.

14. Petrovas C, Vlachouyiannopoulos PG, Kordossis T, Moutsopoulos M. Antiphospholipid antibodies in HIV infection and SLE with or without antiphospholipid syndrome: comparisons of phospholipid specificity, avidity and reactivity with B2-GPI. J Autoimmun. 1999;13:347-55.

15. Massabki PS, Accetturi C, Nishie IA, da Silva NP, Sato El, Andrade LEC. Clinical implications of autoantibodies in HIV infection. AIDS. 1997;11:1845-50.

16. Stimmler MM, Quismorio FP Jr, McGehee WG, Boylen T, Sharma OP Anticardiolipin antibodies in acquired immunodeficiency syndrome. Arch Intern Med. 1989;149:1833-5.

17. Muller S, Richalet $P$, Laurent-Crawford A, et al. Autoantibodies typical of non-organ-specific autoimmune disease in HIV-seropositive patients. AIDS. 1992;6:933-42.

18. Lafeuillade A, Ritter J, Pellegrino P, Qiulichini R, Monier JC. Lack of antinuclear antibodies during HIV infection (correspondence). AIDS. 1993;7:893.

19. Daikh BE, Holyst MM. Lupus-specific autoantibodies in concomitant human immunodeficiency virus and systemic lupus erythematosus: case report and literature review. Semin Arthritis Rheum. 2001;30:18-25.

20. Gindea S, Schwartzman J, Herlitz LC, et al. Proliferative glomerulonephritis in lupus patients with human immunodeficiency virus infection: a difficult clinical challenge. Semin Arthritis Rheum. 2010;40:201-9.

21. Molina JF, Citera G, Rosler D, et al. Coexistence of human immunodeficiency virus infection and systemic lupus erythematosus. J Rheumatol. 1995;22:347-50.

22. Byrd VM, Sergent JS. Suppression of systemic lupus erythematosus by the human immunodeficiency virus. J Rheumatol. 1996;23:1295-6.

23. Fox RA, Isenberg DA. Human immunodeficiency virus infection in systemic lupus erythematosus. Arthritis Rheum. 1997;40:1168-72.

24. Gould T, Tikly M. Systemic lupus erythematosus in a patient with human immunodeficiency virus infection - challenges in diagnosis and management. Clin Rheumatol. 2004;23:166-9. 
25. López-López L, González A, Vilá LM. Long-term membranous glomerulonephritis as the presenting manifestation of systemic lupus erythematosus in a patient with human immunodeficiency virus infection. Lupus. 2012;21:900-4.

26. Gul A, Inanc M, Yilmaz G, et al. Antibodies reactive with HIV-1 antigens in systemic lupus erythematosus. Lupus. 1996;5:120-2.

27. UNAIDS/WHO Working Group on Global HIV/AIDS/STI Surveillance 2001 Guidelines for using HIV testing technologies in surveillance: selection, evaluation and implementation. Available at http://www.who.int/hiv/pub/ epidemiology/pub4/en/.

28. Sperber K, Kalb TH, Stecher VJ, Banerjee R, Mayer L. Inhibition of human immunodeficiency virus type 1 replication by hydroxychloroquine in T cells and monocytes. AIDS Res Hum Retrovir. 1993;9:91-8.

29. Sperber K, Ornstein MH. The anti-inflammatory effect of hydroxychloroquine in two patients with acquired immunodeficiency syndrome and active inflammatory arthritis. Arthritis and Rheum. 1996;39:157-61.

30. Stock $P G$, Roland $M E$, Carlson L, et al. Kidney and liver transplantation in human immunodeficiency virus-infected patients: a pilot safety and efficacy study. Transplantation. 2003;76:370-5.

31. World Health Organization. TB/HIV Facts. Factsheet. Geneva: World Health Organization; 2013. Available at http://www.who.int/tb/challenges/hiv/ factsheets/en

32. Zandman-Goddard G, Shoenfeld Y. Infections and SLE. Autoimmunity. 2005; 38:473-85.

Ready to submit your research? Choose BMC and benefit from:

- fast, convenient online submission

- thorough peer review by experienced researchers in your field

- rapid publication on acceptance

- support for research data, including large and complex data types

- gold Open Access which fosters wider collaboration and increased citations

- maximum visibility for your research: over $100 \mathrm{M}$ website views per year

At BMC, research is always in progress.

Learn more biomedcentral.com/submissions 